\title{
Linking Computational Thinking and BNCC in Primary School: a qualitative study on the perspective of teachers
}

Original Title: Vinculação do Pensamento Computacional com a BNCC no Ensino Fundamental I: um estudo qualitativo sobre a perspectiva dos professores

\author{
Suéllen R. Martinelli ${ }^{1,2}$, Luciana Ap. M. Zaina², Tiemi C. Sakata ${ }^{2}$ \\ ${ }^{1}$ Mestrado em Ciência da Computação, Universidade Federal de São Carlos (UFSCar) - Sorocaba, SP - Brasil \\ ${ }^{2}$ Programa de Pós-Graduação em Ciência da Computação, Universidade Federal de São Carlos (UFSCar) - Sorocaba, SP - Brasil
}

\begin{tabular}{l} 
ARTICLE INFO \\
\hline Article history: \\
Received 08 February 2019 \\
Accepted 07 April 2020 \\
Available online 05 May 2020
\end{tabular}

Keywords:

Computational Thinking BNCC

Primary School

ISSN: $2595-9077$

DOI: JCThink.v3.n1.p19

\section{ABSTRACT}

INTRODUCTION: The incorporation of ways of developing computer skills in primary and secondary education has been a demand in some countries, and practice in others. Among these skills, Computational Thinking (CT) has the aim of working the ability to using mental processing to find out solutions to problems. National Common Curricular Base (BNCC) of Brazil, CT appears strictly applied to the curricular component of Mathematics and focused on the use of technologies. OBJECTIVE: This paper presents the connections between CT and the skills and the subjects found in BNCC. These connections were identified from activities which were created and applied by primary school teachers. METHOD: A practical continuing education course was carried out in which two groups of teachers who had to handle teaching activities that associated CT to BNCC. During the course, the participants were encouraged to create practical activities to be applied in their classrooms afterwards. In total, 33 activities were built by the participants. Later, these activities were examined, and some parts were coding following a qualitative analysis approach. RESULTS: As a result, we found out codes related to actions, concepts and processes that were connected to four subject areas of BNCC. CONCLUSION: Most of the participants had a preference to use unplugged activities and applied different teaching strategies. Additionally, we concluded that the CT is characterized as being a multidisciplinary topic and can be associated with different components of the curriculum. Even having struggled in some activities, we considered the participants could foster among their students the "computational think".

RESUMO

INTRODUÇÃO: A incorporação de formas de desenvolver habilidades de computação no ensino primário e secundário tem sido uma demanda em alguns países e prática em outros. Entre essas habilidades, o Pensamento Computacional (PC) tem o objetivo de trabalhar a capacidade de usar ferramentas mentais para encontrar soluções para os problemas. A Base Curricular Comum Nacional (BNCC), do Brasil, o PC aparece estritamente aplicado ao componente curricular de Matemática e focado no uso de tecnologias. OBJETIVO: Este artigo apresenta as conexões entre o PC e as habilidades e áreas do conhecimento preconizadas pela $B N C C$. Essas conexões foram identificadas a partir de atividades criadas e aplicadas por professores do Ensino Fundamental I. MÉTODO: Realizou-se um curso prático de formação continuada, distribuidos em duas turmas, em que grupos de professores tiveram que lidar com atividades de ensino que associaram o PC à BNCC. Durante o curso, os participantes foram encorajados a criarem atividades práticas para posterior aplicação em suas respectivas salas de aula. No total, 33 atividades foram construidas pelos participantes. Posteriormente, essas atividades foram examinadas e algumas partes foram codificadas seguindo uma abordagem de análise qualitativa. RESULTADOS: Como resultado, identificou-se códigos relacionados as ações, conceitos e processos que foram conectados as quatro áreas do conhecimento da BNCC. CONCLUSÃO): A maioria dos participantes preferiu utilizar atividades desplugadas e aplicou diferentes estratégias de ensino. Além disso, conclui-se que o PC caracteriza-se como um elemento multidisciplinar e pode estar associado a diferentes componentes curriculares. Mesmo com dificuldades em algumas atividades, admite-se que os participantes conseguiram fomentar entre seus alunos o "pensar computacional". 


\section{Introdução}

Sabe-se atualmente que os conhecimentos relacionados à Computação são tão importantes para a vida na sociedade contemporânea, quanto aqueles associados às demais áreas, como Matemática, Linguagens e Ciências (SBC, 2017). Anterior aos conhecimentos que propiciam a fluência do indivíduo em um mundo digital, é preciso estimular nas crianças, um raciocínio analítico e sistemático. O Pensamento Computacional (PC), do inglês Computational Thinking, é definido como um conjunto de habilidades centradas em fundamentos da Ciência da Computação (CC) que auxiliam na interpretação e solução de problemas de todas as áreas do conhecimento, sem ser necessário o emprego de recursos digitais para esse fim. A competência de se "pensar computacionalmente" requer a capacidade de simplificar problemas, desenvolver o raciocínio lógico, analisar fatos, reduzir problemas em partes menores e gerenciáveis, entre outros procedimentos mentais aplicáveis à resolução de problemas (Wing, 2006).

Países como Inglaterra, Irlanda e Portugal já possuem currículos próprios voltados especificamente para o ensino do PC (Balanskat \& Engelhardt, 2015), além de organizações como a Computer Science Teachers Association (CSTA) e a International Society for Technology in Education (ISTE) terem normas que direcionam escolas quanto à inserção da Computação e do PC na educação. No Brasil, a Sociedade Brasileira de Computação (SBC) e iniciativas de universidades efetuam intervenções destinadas à comunidade com o propósito de disseminar esses conhecimentos. Porém, as ações são efetuadas diretamente pelo profissional da Computação (França et al., 2014, Raabe et al., 2017), sem integração com o professor do Ensino Básico.

Este artigo tem como objetivo apresentar a ligação entre o Pensamento Computacional e as habilidades e áreas do conhecimento especificadas pela Base Nacional Comum Curricular (BNCC). Essa ligação foi identificada a partir de atividades de ensino desenvolvidas e mediadas por professores do Ensino Fundamental I (EFI). Esta pesquisa, de cunho qualitativo e descritivo (Creswell, 2014), faz parte de uma investigação mais ampla, em que proporcionou a oferta de uma formação continuada sobre PC. Algumas das práticas desenvolvidas no curso foram acompanhadas pela pesquisadora, a fim de capturar características do ambiente e impressões que ajudassem na descrição dos relatos das experiências de campo. E em um segundo momento, processos de codificação de dados (Gibbs, 2009) foram utilizados para levantar ocorrências sobre como o PC e a BNCC são combinados nessas atividades de ensino. Os professores mostraram-se mais adeptos às atividades desplugadas e utilizaram diferentes estratégias de ensino para mediar tais práticas.

O artigo está organizado como segue: a Seção 2 apresenta conceitos e trabalhos relacionados ao PC na educação básica; a Seção 3 descreve as técnicas e a metodologia geral da pesquisa; a Seção 4 exibe o relato de quatro experiências acompanhadas em classes do EFI; a Seção 5 e suas subseções tratam das relações identificadas entre o PC e a BNCC a partir de códigos qualitativos obtidos; a Seção 6 faz apresenta discussões acerca de algumas premissas levantadas com base na análise qualitativa; e a Seção 7 fornece as considerações finais deste trabalho.

\section{Iniciativas, Conceitos e Trabalhos Relacionados}

Com o propósito de difundir o PC e fornecer subsídios para a sua implantação no Ensino Básico, iniciativas estrangeiras como o CS Unplugged (Bell, Witten \& Fellows, 2011) e a Barefoot CAS (Barefoot, 2014), fornecem materiais didáticos gratuitos de atividades que estimulam esse Raciocínio Computacional nas crianças. Há também grupos brasileiros que oferecem cursos e oficinas à comunidade, como o Computação 
na Escola, o Meninas Digitais, o Computing to You! (C2Y!) e o Laboratório de Inovação Tecnológica na Educação (LITE), além da própria SBC estar em processo de discussão com representantes BNCC quanto à adequação da Base, para incorporar habilidades específicas sobre PC no currículo (Leite \& da Silva, 2017; SBC, 2017).

Apesar de todas essas ações sobre o tema, ainda não existe um consenso por parte dos pesquisadores da Computação e Educação sobre as habilidades que configuram esse "pensar computacional" (Kalelioglu, Gülbahar \& Kukul, 2016). Nesse contexto, este trabalho baseou-se nas habilidades do PC estabelecidas pelas normas da CSTA / ISTE (Computational Thinking Leadership Toolkit), da CSTA / ACM (K-12 Computer Science Standards), da Barefoot (Barefoot, 2014) e da SBC (SBC, 2017), sendo elas: Raciocínio Lógico, capacidade de analisar fatos e estruturar ideias para argumentar sobre um problema; Algoritmos / Procedimentos, capacidade de gerar uma sequência finita de instruções para executar uma tarefa; Decomposição / Generalização, capacidade de quebrar um problema em partes ou de analisar partes para se chegar no todo; Reconhecer Padrões, capacidade de identificar similaridades entre problemas e aplicálas a outras situações semelhantes; Abstração, capacidade de sintetizar fatos com o intuito de definir o que é importante; Paralelismo, capacidade de administrar e distribuir recursos para realizar tarefas forma simultânea e colaborativa; e Manipulação de Dados, capacidade de coletar, avaliar e representar dados de maneira objetiva e sistêmica.

São identificadas na literatura pesquisas recentes com ênfase tanto no levantamento e estruturação de currículos de Computação aplicados à educação (Balanskat \& Engelhardt, 2015; Kalelioglu, Gülbahar \& Kukul, 2016), como também de relatos de experiências e estudos que descrevem ações quanto ao fomento do PC no Ensino Básico brasileiro. Algumas dessas intervenções são: a aplicação de práticas desplugadas sobre CC e efetuadas por licenciandos em Computação em escolas públicas e privadas (França et al., 2014); a condução de atividades desplugadas interdisciplinares sobre CC com alunos do Ensino Fundamental II e Médio, desenvolvidas por docentes da Computação e do Ensino Básico (Ferreira et al., 2015); a formação de um laboratório maker que viabilizou atividades sobre programação e robótica com alunos do Ensino Médio (Raabe et al., 2017); o desenvolvimento de jogos de formato digital como o "Computability Game" (Bombasar, Raabe \& de Santiago, 2017) e de tabuleiro como "A Última Árvore" (da Silva Junior, Cavalheiro \& Foss, 2018), a fim de estimular habilidades do PC nos alunos do Ensino Fundamental.

Este estudo diferencia-se dos mencionados por relatar experiências sobre PC que foram desenvolvidas e aplicadas por docentes do EFI, no qual contaram com a participação da primeira pesquisadora deste estudo como observadora externa, na maioria dos casos. A principal contribuição desse estudo é apresentar a relação identificada entre as habilidades da BNCC e as do PC, desenvolvidas de maneira concomitante em todas as práticas de ensino avaliadas.

\section{Metodologia, Procedimentos e Materiais}

A pesquisa descritiva é considerada uma metodologia que visa analisar fatos e/ou fenômenos, a fim de realizar uma descrição em profundidade sobre uma realidade pesquisada. Para suportar esse tipo de pesquisa científica, tem-se na observação, uma técnica amplamente usada em investigações qualitativas, que visa coletar dados com base no ato de presenciar um fenômeno em campo, com propósitos científicos e apoiado por instrumentos de registro (Creswell, 2014). Este estudo se enquadra à uma pesquisa descritiva, com o propósito de sintetizar e expor relatos de observações concretizadas em escolas de educação básica. Essas narrações descrevem experiências de práticas de ensino relacionadas ao PC, desenvolvidas e conduzidas por professores do EFI, 
acompanhadas por um profissional da Ciência da Computação. A Figura 1 apresenta a metodologia e as ações empregadas para a obtenção e avaliação dessas práticas de ensino.

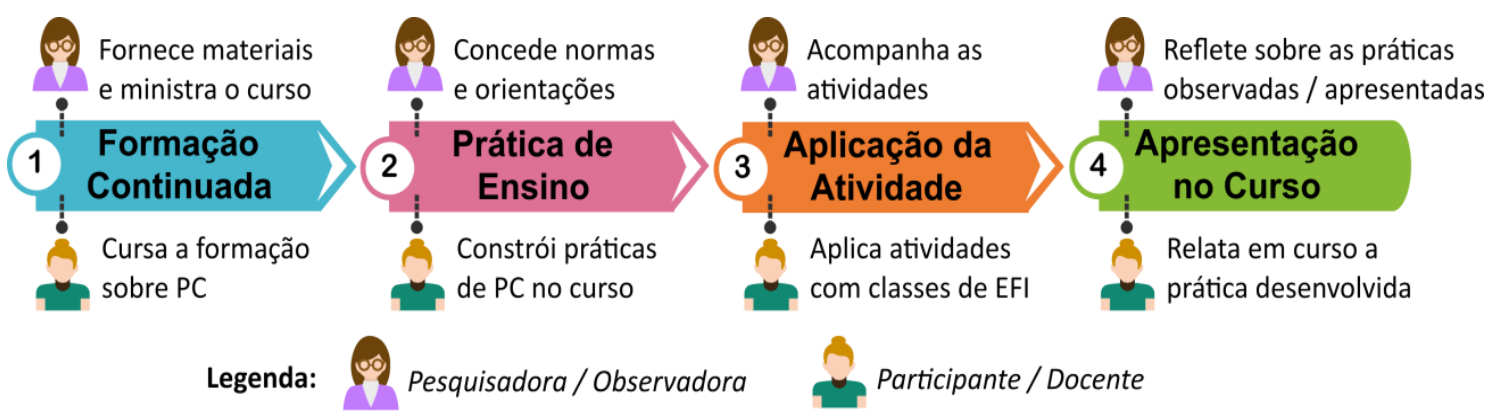

Figura 1. Ações sobre o desenvolvimento do estudo, mediado por uma investigação qualitativa.

Na etapa 1) Formação Continuada foi ofertada à comunidade uma formação continuada (atividade de extensão) sobre PC para atender docentes em exercício no EFI e demais interessados. Ofertou-se duas turmas de 40 vagas cada do mesmo curso, uma na UFSCar - Câmpus Sorocaba e outra na IFSP - Câmpus Itapetininga. O curso foi ministrado pela primeira autora e aplicado durante o primeiro semestre de 2018. De caráter semipresencial, as 8 aulas presenciais foram ministradas em encontros quinzenais, com duração de 180 minutos cada. Para as 6 aulas de formato EaD foram disponibilizados materiais ${ }^{1}$, vídeos ${ }^{2}$ e suporte online no mesmo dia e horário dos encontros presenciais. Durante o curso, explorou-se o PC nas diferentes áreas de conhecimento, além de apresentar estratégias de ensino como atividades plugadas / desplugadas, Cultura Maker, práticas voltadas para robótica e programação (com kits como o Makey Makey e aplicações como o Scratch e o Code.org) bem como o uso de diferentes Objetos de Aprendizagem (OAs).

A etapa 2) Prática de Ensino representa o desenvolvimento de práticas de ensino que integram o PC aos conteúdos e habilidades exigidas por cada componente curricular, em conformidade com a BNCC. O desenvolvimento dessas atividades foi requisito de avaliação na formação continuada e ocorreu em dois momentos, que representaram a elaboração de duas atividades de ensino distintas. Os critérios estabelecidos para a construção das práticas foram: i) compor grupos de 3 a 4 pessoas; ii) documentar a ação de ensino em um formato determinado de plano de aula; iii) organizar e produzir artefatos para uso nas práticas, de caráter digital ou não; iv) aplicar a atividade em uma classe do EFI por um ou mais integrantes (etapa exigida apenas na primeira entrega) e, v) efetuar correções no plano de aula de acordo com a experiência, se necessário.

A aplicação dessas práticas entre estudantes do Ensino Básico desencadeia a etapa 3) Aplicação da Atividade, na qual foi empregada a técnica de observação participante, em que a primeira pesquisadora deste estudo acompanhou as atividades nas escolas onde foram aplicadas, para observar a experiência em campo, mas sem intervir nas ações dos docentes e dos alunos durante as práticas. Para essa atuação foi necessário o uso de um protocolo observacional como mecanismo manual de registro, composto por: cabeçalho, como identificador geral sobre a atividade observada; notas descritivas, para retratar informações do ambiente físico, eventos e ações dos envolvidos e notas

\footnotetext{
1 Acesse a documentação de algumas das atividades ministradas e tutoriais desenvolvidos para a formação em: http://www.c2yensina.ufscar.br ou http://bit.ly/AtividadesFormacaoPC.

${ }^{2}$ Acesse a playlist das aulas dadas na formação em: http://bit.ly/C2Yplaylist.
} 
reflexivas, para descrever hipóteses, impressões e aprendizados por parte do observador (Creswell, 2014).

A apresentação das práticas, equivalente à etapa 4) Apresentação no Curso, possibilitou a exposição dos planos de aula documentados, dos artefatos produzidos e/ou utilizados nas práticas e forneceu espaço para relatos dos docentes quanto às atividades desenvolvidas pelos grupos. Para a análise dessa etapa foi adotada o uso da técnica de codificação, com o propósito de identificar padrões em trechos de textos ou partes de figuras, agrupando-os em coleções de dados capazes de expressar algum aspecto comum (Gibbs, 2009). Esta análise, realizada pelas autoras, permitiu localizar similaridades entre as práticas de ensino elaboradas pelos participantes, com foco nas habilidades da BNCC e no levantamento de atributos que caracterizam essas atividades direcionadas ao PC.

A codificação considerou quatro elementos principais vinculados à análise das práticas documentadas: i) os protocolos observacionais, documento para anotações livres, estruturado com notas descritivas e reflexivas do ambiente observado; ii) os registros digitais das atividades, compostos por fotos, áudios e vídeos, capturados diante da autorização das escolas visitadas; iii) os planos de aula, elaborados pelos grupos de professores durante a formação continuada e entregues via ambiente EAD; e iv) o documento eletrônico da BNCC, em sua versão final (BNCC, 2018). A avaliação desses documentos $^{3}$ sustentam as seções seguintes, que visam mostrar alguns relatos de experiências, resultados da análise qualitativa e discussões das vivências de campo quanto ao desenvolvimento do PC no Ensino Básico.

\section{Relatos de Experiências das Práticas de Ensino sobre PC}

Com 26 docentes concluintes em cada uma das turmas da formação continuada e totalizando 52 participantes, foram recebidas 33 atividades ${ }^{4}$ de ensino documentadas (planos de aula), aos quais 21 dessas foram aplicadas no EFI e 13 contaram com a presença da pesquisadora (observação participante). Das práticas documentadas e aplicadas, 17 escolas distintas foram atendidas $(70,5 \%$ entre instituições públicas e 29,5\% em colégios privados) por experiências que estimularam o Raciocínio Computacional em crianças do EFI, distribuídas entre três municípios do interior do estado de São Paulo, sendo eles Alambari, Itapetininga e Sorocaba.

Dessas 33 atividades, quatro experiências foram selecionadas para serem relatadas. A seleção destas priorizou expor práticas que atenderam a diferentes habilidades do PC e a componentes curriculares distintos. Os relatos estão baseados na observação realizada pela primeira pesquisadora do estudo e são descritos em ordem cronológica de aplicação das atividades.

A atividade "Bingo Binário", sobre Matemática (EF02MA05) ${ }^{5}$, teve como objetivo trabalhar a capacidade de reconhecer padrões entre sistemas numéricos distintos (decimal e binário), a partir do desenvolvimento do cálculo mental com adição.

Notas Descritivas: Para estimular esse raciocínio entre crianças do $2^{\circ}$ ano, foi projetado um tapete de 15 espaços ocupados por um padrão binário de quatro bits e com sequências distintas de símbolos $(\bullet=0$ e $\boldsymbol{\vee}=1)$, um cartaz com informações sobre a posição binária e o valor decimal de cada bit, e bolinhas numeradas entre 1 e 15 . Inicialmente, a professora revisou conceitos sobre o que é um sistema binário e deu

\footnotetext{
3 Acesse os modelos de Protocolo Observacional e de Plano de Aula, respectivamente, em: http://bit.ly/ProtocoloObservacao e http://bit.ly/ModeloPlanoAula.

${ }^{4}$ Acesse dados sobre as atividades desenvolvidas pelos participantes em: http://bit.ly/DadosAtividades.

${ }^{5}$ A seção exibe códigos de habilidades da BNCC (BNCC, 2018). Consulte-o para mais informações.
} 
exemplos de aplicação no cotidiano, utilizando esse modelo. Depois, com a classe divida em dois grupos, a docente sorteava um número, e as equipes tinham 30 segundos para avaliarem qual sequência binária do tapete seria equivalente ao decimal para, em seguida, um dos membros do grupo pisar em um espaço-alvo. $\mathrm{O}$ primeiro discente a pisar na sequência explica aos demais como o grupo chegou no resultado (soma das posições com $\vee$ ). Após várias rodadas, o grupo com mais pontos vencia a gincana. Notas Reflexivas: Entre 20 rodadas feitas, próximo da décima, foi retirado o cartaz de apoio. Os alunos resolveram cada rodada, em média, na metade do tempo fornecido (15 segundos), e se mostraram motivados e entusiasmados com a atividade. A prática propiciou um ambiente colaborativo e apontou o uso de estratégias como Gamificação, por usar pontuação e proporcionar desafios; além do uso de Objetos de Aprendizagem, como o tapete e o cartaz criados pelos professores envolvidos.

Já a atividade “Localização por Coordenadas”, sobre Geografia (EF02GE10), teve como propósito a construção de algoritmos / procedimentos por parte das crianças, para que elas aplicassem conhecimentos sobre coordenadas, localização, movimentação e orientação, mediados pela rosa dos ventos. Notas Descritivas: O cenário da atividade foi composto por um tapete de TNT com quadrados coloridos e impressões em A3 de diferentes locais (escola, parque, hospital, etc). A atividade contou com a participação de duas classes do $4^{\circ}$ ano, sendo cada classe, uma equipe. A partir de diversas missões, como 'sair da escola e chegar até o hospital', e com comandos determinados pelas direções da rosa dos ventos, as equipes projetaram seus algoritmos definindo o número de passos para cada direção. Após montado o algoritmo, o mesmo era executado por um membro da turma e depurado com a ajuda das professoras e dos demais colegas. Notas Reflexivas: Na tentativa de fazer a maioria das crianças participarem (em torno de 50 alunos), foram feitas muitas rodadas, tornando a atividade um pouco cansativa aos discentes. Uma sugestão para tornar cada rodada mais desafiadora, seria trocar os locais nos pontos do tapete. Os OAs desenvolvidos pelas professoras para a dinâmica foram doados à escola, uma vez que outros docentes se interessaram pela prática.
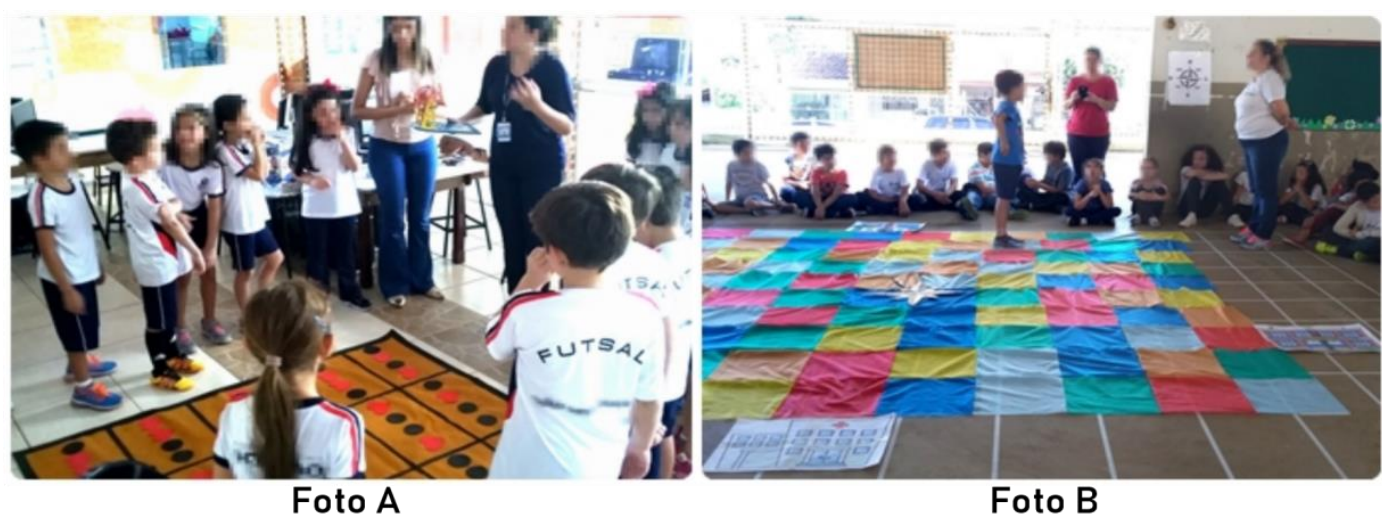

Figura 2. Registros das atividades "Bingo Binário" (Foto A) e "Localização por Coordenadas” (Foto B).

A prática “Desafios no Scratch", relacionada à Matemática (EF03MA08), trabalhou a interpretação e a manipulação de dados, a fim de organizar termos-chave (comandos) em categorias, para posterior montagem de procedimentos usando o Scratch. Notas Descritivas: em trios, os alunos do $3^{\circ}$ ano receberam cartões com um algoritmo no formato de texto instrucional. No texto, os termos em destaque correspondem aos comandos do Scratch. Os alunos receberam também um guia que mostra todos os comandos de cada categoria, de acordo com o Scratch. Na etapa desplugada, as crianças identificaram a categoria de cada um dos termos em destaque no algoritmo fornecido. 
Essa organização de dados auxilia as equipes para a etapa plugada, onde os grupos se reúnem com a docente frente a lousa digital, para construírem os códigos, a partir do algoritmo e dos comandos categorizados. Notas Reflexivas: Durante a observação, a professora relata que a ideia inicial era conduzir a prática no laboratório de informática, mas que o mesmo se encontrava em manutenção desde 2017. Havendo apenas um computador para uso dos alunos, seria interessante que cada trio programasse no Scratch, individualmente, uma missão, para ter o envolvimento de todos os discentes. Mesmo assim, os alunos ficaram entusiasmados, especialmente na etapa plugada da atividade.

A atividade "Investigando Solos", aplicada em uma escola rural e relacionada com Ciências (EF03CI09), promoveu o desenvolvimento da habilidade de abstração por meio da análise e comparação de diferentes amostras de solos, com o intuito de identificar características entre eles. Notas Descritivas: A atividade usa três amostras de solos, um computador, um projetor e outros materiais diversificados. As professoras fazem uma introdução sobre o que é o PC e utilizam vídeos para instruir os alunos sobre a prática (montagem de um microscópio caseiro com um smartphone, uma lente de webcam e massinha de modelar). Os alunos são divididos em dois grupos, e cada equipe fica responsável por montar um microscópio para uso colaborativo. Com os dispositivos montados, cada docente conduz um grupo na observação dos solos, que durou aproximadamente 15 minutos. Durante a análise, as professoras argumentavam sobre propriedades desses solos, além de tirarem fotos, sendo elas impressas na secretaria da escola. Na etapa desplugada, cada criança recebe uma ficha de observação para experimentos (fornecida no curso de formação continuada), para registrar características de composição dessas amostras (cor, textura, cheiro, tamanho das partículas, etc.) e colar uma foto de cada amostra descrita. Notas Reflexivas: A prática despertou o interesse e a atenção dos alunos, especialmente na fase de observação das amostras. Percebe-se a facilidade dos alunos em fazer relações entre o conteúdo abordado e o cotidiano dos estudantes. Essa prática foi uma das poucas que incorporaram a Cultura Maker como estratégia de ensino, na primeira etapa da prática, além dos próprios OAs.

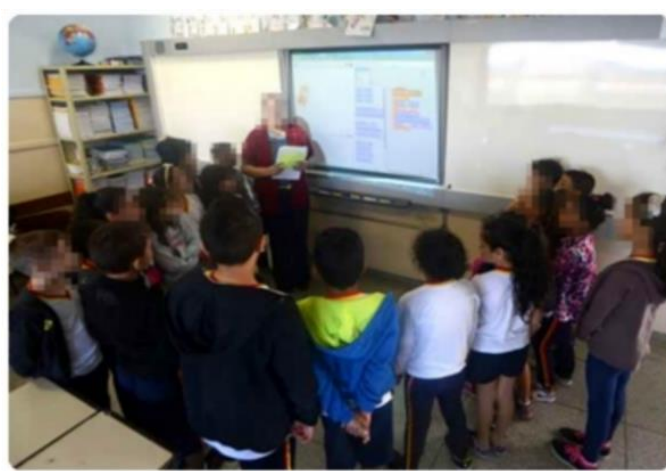

Foto $\mathrm{A}$

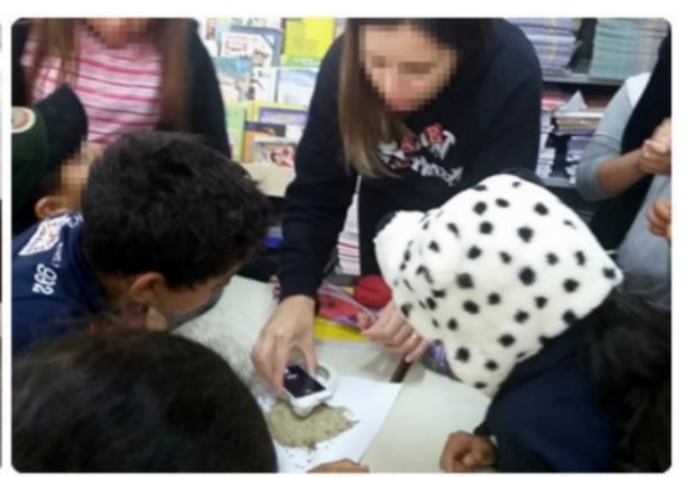

Foto $\mathrm{B}$

Figura 3. Registros das atividades "Desafios no Scratch" (Foto A) e "Investigando Solos" (Foto B).

\section{Relações entre a BNCC e o Pensamento Computacional}

Uma das normas mais recentes e que influenciam as escolas brasileiras quanto à adequação de seus currículos é a Base Nacional Comum Curricular. Na versão homologada do respectivo documento (BNCC, 2018), o termo Pensamento Computacional é mencionado somente quatro vezes dentre as 468 páginas que compõem o documento. Essas citações são feitas no resumo de abertura da área do 
conhecimento de Matemática, caracterizando o PC como algo exclusivo a ser desenvolvido junto com a Matemática.

De fato, não é difícil identificar pontos de intersecção entre o que é do pensamento 'algébrico' e do 'computacional'. Expressões como representar, formular, generalizar, padronizar, identificar, analisar e resolver problemas enfatizam uma conexão natural entre o PC e a Matemática. Todavia, o diferencial do PC reside em ser uma capacidade que possibilita novas e diferentes abordagens criativas para a resolução de problemas, no qual pode ser empregada em uma ampla gama de atividades pelos estudantes, em todos os níveis de ensino (Valente et al., 2017).

A própria Base define que o significado de habilidades como sendo caracterizadas relacionadas à ações, conceitos e processos que devem ser desenvolvidos nos alunos durante todo o Ensino Básico (BNCC, 2018). Tendo como conhecimento que o PC é uma reunião de habilidades aplicáveis à resolução de problemas de diversas áreas do conhecimento (Wing, 2006), esta análise avaliou quais são os elementos, ou seja, as ações, conceitos ou processos que caracterizam as habilidades da BNCC exploradas em práticas de ensino, de maneira concomitante com aquelas associadas ao PC.

\subsection{Os códigos qualitativos: características das habilidades da Base}

Diante da premissa pontuada na seção anterior e da aplicação das técnicas de pesquisa qualitativa determinadas por este estudo, foi possível concretizar os códigos qualitativos expostos no Quadro 1. Ele reúne as ações, conceitos e processos mais frequentes identificados nas práticas, sendo esses elementos relacionados ao conteúdo da BNCC e às habilidades do PC. Os códigos são dados por sentenças e agrupados pelas quatro áreas do conhecimento ${ }^{6}$ atendidas pelo EFI. Para facilitar a identificação dos códigos foi estipulada uma sigla para cada sentença, respeitando a inicial do nome do componente curricular $^{7}$, acompanhado de um número sequencial.

Linguagens
(LP01) Reconhecer diferentes gêneros
textuais.
(LP02) Reconhecer letras e/ou compor
palavras.
(LP03) Interpretação de linguagem
verbal e não verbal.
(LP04) Produção e/ou interpretação
colaborativa de texto.
(AR01) Explorar brincadeiras regionais.
(AR02) Uso de softwares e multimídias
na produção / criação artística.

\section{Matemática}

(MA01) Interpretação e manipulação de dados em tabelas.

(MA02) Aplicação de medida padronizada.

(MA03) Problemas sobre situações comerciais e sistema monetário.

(MA04) Aplicabilidade das operações fundamentais.

(MA05) Identificar e representar frações.

(MA06) Estratégias de cálculo mental e estimativa.

(MA07) Quantificação, agrupamento e ordenação de objetos.

(MA08) Trajetos e pontos de origem / destino.

(MA09) Deslocamentos e mudanças de direção, sentido e giro.

\footnotetext{
${ }^{6}$ As áreas do conhecimento abordadas no EFI são classificadas em: Linguagens, Matemática, Ciências da Natureza e Ciências Humanas (BNCC, 2018).

7 As siglas são respectivas à Língua Portuguesa (LP), Artes (AR), Matemática (MA), Ciências (CI), Geografia (GE) e História (HI).
} 
(AR03) Uso de diferentes técnicas e materiais na composição de artes visuais.

\section{Ciências da Natureza}

(CI01) Identificar constelações.

(CI02) Reciclagem e identificação de recicláveis.

(CI03) Plantas e etapas de plantio.

(Cl04) Identificar e comparar propriedades entre materiais / objetos.

(CI05) Construção de dispositivos óticos.
(MA10) Composição de formas geométricas e/ou análise de seus atributos.

(MA11) Solução de um mesmo problema com diferentes algoritmos.

\section{Ciências Humanas}

(GE01) Aspectos sobre economia, processos de produção e consumo.

(GE02) Pontos cardeais e de referência.

(GE03) Interpretação e/ou representação de espaços e mapas.

(HI01) Papéis sociais das pessoas nas comunidades.

(HI02) Comparação de diferentes

linguagens e seus aspectos culturais.

Quadro 1. Códigos identificados na análise qualitativa e separados por área de conhecimento.

Das quatro áreas do conhecimento atendidas, apenas o componente curricular de Educação Física não foi identificado nas práticas analisadas. Em contra partida, todas as sentenças representam temas, ações ou conceitos chaves que foram explorados juntos de uma ou mais habilidades do PC. Para essa constatação foram consideradas as fundamentações ${ }^{8}$ e correlações ${ }^{9}$ efetuados entre as categorias do Quadro 1 e aquelas respectivas às habilidades do PC. As maiores correlações apresentadas na área de Linguagens foram entre o código LP04 e a habilidade de Algoritmos/ Procedimentos, com um percentual de correlação de 9\%, e entre o AR02 e o Paralelismo, que resultou em $16 \%$. Esses resultados representam que atividades de ensino que mais fomentaram habilidades da Base e do PC, abordaram temas como a produção e/ou interpretação colaborativa de texto (LP04), bem como o uso de softwares e multimídias na criação / produção artística (AR02). Em Matemática, houve um empate percentual de $10 \%$ na correlação entre o código MA06 e as habilidades de Decomposição / Generalização, Algoritmos / Procedimentos e Abstração, além da maior concentração de correlação da área ocorrer entre o MA01 e a Manipulação de Dados, com 32\%. Nas demais áreas as maiores correlações identificadas foram entre o CI04 e a Abstração (em Ciências da Natureza), e entre o GE03 e a Manipulação de Dados (em Ciências Humanas), ambas com $6 \%$ cada.

Contudo, mais importante que os resultados de correlação é observar que diferente da argumentação exposta pela BNCC, o PC é uma competência pertinente de ser desenvolvida em todas as áreas do conhecimento, e não apenas na Matemática. Isso leva a uma inferência associada a multidisciplinaridade, com base na presença do PC e sua relação com diversos componentes curriculares pela Base. A multidisciplinaridade é definida como uma justaposição de disciplinas ou conteúdos, aplicados ao estudo de um

\footnotetext{
8 Em codificação, a fundamentação de um código equivale a quantidade de citações reunidas no respectivo elemento, equivalentes a trechos de textos ou imagens que caracterizam o nome dado ao respectivo código (Gibbs, 2009).

${ }^{9}$ É um cruzamento obtido a partir de matrizes relacionais que computam o valor percentual de citações igualmente identificadas entre dois códigos (Gibbs, 2009).
} 
determinado assunto ou na resolução de um problema. A articulação de técnicas e procedimentos de diferentes componentes curriculares faz com que estes sejam abordados de maneira paralela, sem a preocupação de interligar as disciplinas entre si (Creswell, 2014). Essa perspectiva, quando articulada em uma prática de ensino, requer do aluno a obtenção de informações de uma ou mais ciências para a resolução de um determinada problemática (Pires, 1998). Pode-se dizer então que tal definição institui uma característica do $\mathrm{PC}$, uma vez que o fomento dessa competência frente à solução de um caso ou problema é pautado por temas, conceitos ou processos distintos, que também dependem de outros conhecimentos próprios de cada componente curricular. Portanto, todas as práticas obtidas e avaliadas por este estudo são de caráter multidisciplinar por expor a ideia de justaposição do Raciocínio Computacional e sua mobilização com todas as áreas do conhecimento, a partir das ações, conceitos e processos identificados e discutidos nessa seção.

\subsection{O Formato de Atividade de Ensino Comprimido (FAEC)}

As técnicas qualitativas, em especial os processos de codificação aplicados aos documentos e dados recolhidos por este estudo, levantaram também códigos associados ao desenvolvimento das práticas de ensino produzidas pelos participantes. A combinação entre esses objetos resumem uma abordagem aplicada pelos envolvidos nas formações ministradas e que engloba as principais categorias obtidas na análise qualitativa. Essa abordagem recebeu o nome de Formato de Atividade de Ensino Comprimido (FAEC), justamente por representar princípios articulados pelos pesquisados na composição de práticas de ensino voltadas ao PC. O FAEC, dado pela Figura 4, exibe ao centro os elementos (categorias) internas, representadas pela ilustração do diagrama de venn, e outros três elementos na área externa, vinculados as setas.

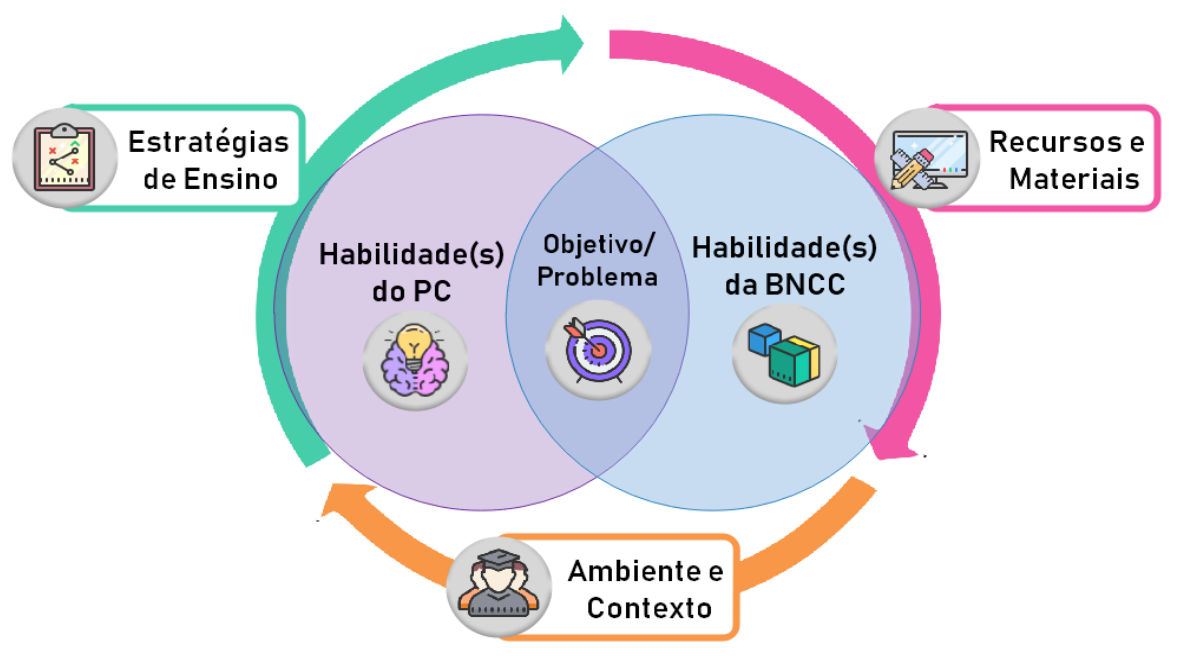

Figura 4. Formato de Atividade de Ensino Comprimido (FAEC)

A interpretação do esquema necessita ser feita a partir dos elementos internos, dados no diagrama de venn, e expandida para os elementos externos. Os elementos internos do FAEC são definidos e caracterizados como:

- Habilidade(s) do PC - definição de qual(is) habilidade(s) alinhadas à competência do Raciocínio Computacional devem ser estimuladas nos discentes, a partir da resolução de um problema proposto (objetivo) pela atividade.

- Habilidade(s) da BNCC - determinação de qual(is) habilidade(s) respectivas a um componente curricular e preconizada(s) pela Base Nacional Comum 
Curricular necessitam ser desenvolvidas nos estudantes, diante da resolução de um problema proposto (objetivo) pela atividade.

- Objetivo / Problema - construção e definição quanto ao propósito da atividade, ou seja, qual o problema ou objetivo fixado que espera-se que a criança resolva ou alcance. A proposta desenvolvida precisa atender as especificidades das habilidades do PC e da BNCC elencadas, a fim de que o aluno empregue ou desenvolva essas habilidades a partir do objetivo e/ou problema dado.

Com a definição dos elementos internos, os professores determinam características, processos ou recursos relacionados aos meios de condução, no caso, como e a partir do que esperam conduzir a atividade de ensino com seus alunos. Assim, os elementos externos do FAEC são compreendidos como:

- Estratégias de Ensino - definições sobre como estimular as habilidades elencadas, ao utilizar de uma ou mais estratégias ou técnicas de ensino para organizar e/ou mediar a atividade.

- Recursos e Materiais - escolha sobre o que precisa ser usado para conduzir a atividade, ou seja, itens como materiais de custo reduzido ou recursos digitais e softwares a serem usados na prática.

- Ambiente e Contexto - fixa-se quais são os aspectos e/ou características que influenciam na prática de ensino, no caso, itens como os locais de condução da atividade, particularidades de infraestrutura da escola, ou mesmo dificuldades institucionais são fatores levados em consideração pelos docentes e que interferem na condução da prática.

Os conteúdos identificados nas práticas de ensino e respectivos aos elementos internos do FAEC fazem conexão com todos os resultados discutidos anteriormente na Seção 5. Quanto aos elementos externos, outros códigos qualitativos identificados destacam, por exemplo, quais foram as Estratégias de Ensino e os Recursos e Materiais utilizados pelos participantes. Entre as Estratégias de Ensino categorizadas a partir das práticas destinadas ao PC, foram reconhecidas: a Aprendizagem Baseada em Problemas, a Cultura Maker, a Gamificação, a de Objetos de Aprendizagem, a Produção de Animações e/ou Narrativas Digitais, a Produção de Simulações e/ou Jogos Digitais, a Programação Visual com Blocos Lógicos e os Temas/Assuntos sobre Computação.

Já nos Recursos e Materiais, foram localizados os mais diversos tipos de materiais aplicados nas práticas, considerando tanto aqueles voltados para atividades desplugadas, representados por materiais do cotidiano e de baixo valor, como também aqueles usados nas atividades plugadas, como softwares e ferramentas digitais. Assim, desse elemento foram extraídas os códigos que definem os principais atributos dos materiais utilizados, sendo essas propriedades reconhecidas como: os materiais de baixo custo, os materiais recicláveis, os materiais escolares e de papelaria, as Linguagens de Programação Visual baseada em Blocos Lógicos, os jogos, simulações e animações, as ferramentas digitais e as Tecnologias Digitais de Informação e Comunicação (TDIC) e os componentes eletrônicos e/ou hardwares.

Diferente do que se imaginava ao início dessa investigação, durante a realização das formações ministradas e da construção das atividades pelos pesquisados, uma mesma prática de ensino pode agregar mais de uma habilidade, tanto respectiva ao Pensamento Computacional, como pela BNCC. Esse foi um aspecto identificado não somente na análise qualitativa desenvolvida, como também pelos próprios professores, ao longo do curso, de acordo com o envolvimento destes na produção das atividades. A 
média de concepções, atendidas por cada prática, ficou em torno de três habilidades para o PC e duas para a BNCC.

\section{Discussões}

Os resultados e as reflexões obtidas com base na análise dos planos de aula, dos relatos pessoais dos participantes e dos demais artefatos e materiais que compuseram o processo analítico-qualitativo, viabilizaram a discussão sobre algumas inferências levantadas. Cada argumento é destacado por uma premissa, acompanhada de colocações que sustentam a interpretação de cada hipótese emergente.

'A maioria dos docentes optaram por atividades de caráter desplugado': os participantes justificaram que a escolha desse formato se deu por se sentirem mais confiantes quanto à organização e mediação de uma prática que, de fato, conseguisse estimular o PC, mesmo nos casos em que as escolas tinham recursos digitais. Uma segunda justificativa sobre essa premissa refere-se as dificuldades de infraestrutura ou de manutenção dos ambientes educacionais dos professores, aos quais inviabilizam qualquer tipo de prática de caráter plugado. Entre os dados capturados de outros formulários, dos 52 concluintes das formações ministradas, não possuem Internet cabeada (21\%), Internet wi-fi (12\%), laboratório de informática $(40 \%)$ ou notebooks (37\%) em suas escolas. Mesmo com dificuldades pessoais e/ou institucionais por parte dos envolvidos, houve um aumento nas práticas plugadas desenvolvidas na segunda avaliação das formações ministradas, o que sugere que os docentes passaram a se sentir mais seguros no uso de recursos ou Objetos de Aprendizagem digitais.

'Poucas práticas integraram um tema/assunto específico da Computação': somente sete, das 33 atividades produzidas, envolveram assuntos próprios da Ciência da Computação. Entre essas sete atividades, duas delas abordaram o sistema binário e, outras duas, sobre redes de computadores. As demais, trataram de ordenação por bubble-sort, grafos e composição de imagens por pixels. De acordo com as observações feitas e com os relatos dos participantes, mesmo em classes do início do EFI, as crianças demonstraram facilidade em resolver problemas a partir de influências, regras ou contextos baseados em temas da Computação, além de mostrarem entusiasmo e curiosidade com conteúdos e assuntos da $\mathrm{CC}$ que, de maneira direta ou indireta, fazem parte do cotidiano do aluno.

'A necessidade da composição de grupos com um docente do EFI para a troca de conhecimentos': alguns grupos foram afetados pela evasão de professores na primeira avaliação das formações mediadas. Grupos que permaneceram com pelo menos um docente do Ensino Básico conseguiram organizar e administrar facilmente práticas de PC, até mesmo, incluindo assuntos de Computação. Porém, equipes que permaneceram com integrantes de outras áreas, somente da Computação ou sem qualquer experiência no Ensino Básico, tiveram dificuldades. Essa complexidade foi vista na documentação da prática, em abstrair como a atividade seria com as crianças e, principalmente, na condução da atividade, ao qual algumas variáveis saíram do planejado, ou seja, a prática de sala de aula apresentou pontos divergentes quanto ao plano de aula documentado.

'Estratégias de ensino distintas e ambientes/cenários diferentes do cotidiano do aluno fomentam o Raciocínio Computacional': entre todas as estratégias de ensino empregadas na formação continuada, a Gamificação e os OAs foram as mais usadas pelos professores nas atividades com as crianças. Por incorporar essas estratégias, elementos como a separação dos alunos em grupos, regras, pontuação e rankings foram quase sempre aplicados nas atividades. Uma abordagem que não foi utilizada pelos 
participantes é a Robótica Educacional, o que, provavelmente, se justifica por apenas três professores de escolas privadas terem acesso a kits ou hardwares para atuarem com essa técnica. Uma estratégia que não foi abordada em curso, mas se mostrou presente em três práticas documentadas é a Aprendizagem Baseada em Problemas. Atividades que usaram dessa técnica deram foco em habilidades como Manipulação de Dados, Paralelismo e Decomposição / Generalização, além de envolver os alunos em um processo de criação e autonomia.

'Os docentes relatam possibilidades de como estimular o Pensamento Computacional no Ensino Infantil': ao longo do curso, em vários momentos entre as práticas efetuadas em aula e nas apresentações dos docentes sobre as atividades elaboradas em grupo, os participantes com experiência ou em atuação no Ensino Infantil, indicavam sugestões de adaptações das práticas para esse público, além de relacionarem como o PC poderia ser estimulado. A maioria dessas sugestões associadas ao contexto infantil atendiam as habilidades de Reconhecer Padrões e Decomposição / Generalização.

'A mudança de perspectiva causada nos professores quanto à incorporação do Pensamento Computacional em sua prática docente': ao término das formações ministradas, em um momento reservado para discussões no último dia de aula, os professores puderam expor suas considerações e reflexões acerca do curso. Esses comentários e sugestões também puderam ser redigidos pelos mesmos, por meio de um formulário eletrônico. Entre as respostas obtidas em aula e nos formulário, observa-se um impacto positivo causado na mudança de compreensão e posicionamento dos envolvidos sobre como estimular o PC em suas salas de aula, bem como o entusiasmo em repassar tais conhecimentos aos demais colegas de profissão. Essa argumentação é sustentada pela apresentação de dois dos vários comentários extraídos dos formulários:

"O curso foi ótimo! Um didática prática e de fácil compreensão; é bem que o que esperamos encontrar, atividades práticas e inovadoras para serem conciliadas com o planejamento escolar, de modo a possibilitar que nós professores desenvolvamos o Pensamento Computacional no aluno." [Participante A]

"Quero agradecer a todos os envolvidos, por toda dedicação em compartilhar conosco esse curso, que nos deu uma nova perspectiva de trabalho, nos impulsionando à reflexão sobre nossas práticas e no aprendizado das habilidades do Pensamento Computacional alinhado com a BNCC. O curso nos ajudou a adequarmos as nossas práticas para a nossa realidade de trabalho, nos fazendo enxergar que é possível a aplicação desses conhecimentos no cotidiano, para ajudar nossos alunos a adquirirem habilidades que serão de grande valia em suas carreiras. As aulas foram claras, estimularam nossa aprendizagem e crescimento profissional. Desejo sucesso a todos e mais cursos inspiradores como esse! Obrigada." [Participante B]

\section{Considerações Finais}

Este artigo apresentou relatos de experiências e resultados de uma análise qualitativa, a partir de práticas de ensino relacionadas ao Pensamento Computacional, desenvolvidas e aplicadas por docentes do Ensino Fundamental I. Com base em uma pesquisa qualitativa e descritiva, suportada por técnicas de observação e codificação, foi possível obter algumas conclusões e vivências de como o professor do Ensino Básico efetua a 
relação entre o PC com os componentes curriculares, e como essa associação é empregada em práticas de ensino que engajem as crianças. Os resultados expostos por este estudo também discutiram a ocorrência do PC com diversas habilidades da Base, comprovando que o Raciocínio Computacional possui caráter multidisciplinar e pode ser abordado em problemáticas de diversas áreas do conhecimento. Outro aspecto importante foi a obtenção do FAEC e a compreensão de como os docentes pensaram em estruturar suas práticas de ensino, com ênfase no PC.

Apesar de ser um assunto desconhecido aos professores que fizeram o curso, ao final da formação, eles declararam que esse "pensar computacional" é algo intrínseco em suas práticas educacionais e que o esclarecimento sobre esse conjunto de habilidades facilitou a maneira de estimulá-las nos discentes. Mesmo porque, o fomento a essa competência independe dos recursos digitais oferecidos pela escola. É claro que, softwares, kits de robótica e computadores enriquecem muito a experiência dos alunos; porém, a falta deles nas escolas não impede o docente de propiciar práticas motivadoras, que desenvolvam o raciocínio analítico e sistemático do aluno. Para novas possibilidades de pesquisa, estudos que abordem sobre o PC na Educação Infantil têm potencial de investigação, uma vez que essa conexão foi reforçada por participantes da formação.

Acredita-se que este estudo também conseguiu atingir ao tripé que rege o processo de ensino-aprendizagem das instituições federais brasileiras, constituído pelo ensino, a pesquisa e a extensão. A partir de investigações coletivas desenvolvidas por membros do Computing to You! (C2Y!), este estudo, em particular, promoveu a interação da universidade com a população e a difusão do conhecimento produzido na academia entre professores do Ensino Básico, de maneira prática e aplicável no cotidiano dos envolvidos.

\section{Agradecimentos}

O presente trabalho foi realizado com apoio da Coordenação de Aperfeiçoamento de Pessoal de Nível Superior - Brasil (CAPES) - Código de Financiamento 001. Agradecimentos às escolas que permitiram a visita da primeira autora, ao Prof. Me. Wilton Moreira Ferraz Junior (IFSP Câmpus Itapetininga), e aos alunos Maylon Pires Macedo e Yuri Souza Padua (C2Y!).

\section{Referências}

BALANSKAT, A.; ENGELHARDT, K. Computing our future: Computer programming and coding. Priorities, school curricula and initiatives across Europe. European Schoolnet, 2015. 87 p.

BAREFOOT. Primary Computing Resources - Concepts: Computational Thinking. 2014 Disponível em: <https://barefootcas.org.uk>. Acesso em: 19/07/2016.

BELL, T.; WITTEN, I. H.; FELLOWS, M. Computer Science Unplugged: Ensinando Ciência da Computação sem o uso do computador. CSUnplugged. Traduzido por Luciano Porto Barreto. 2011. 105 p.

BNCC. Base Nacional Comum Curricular: Educação é a Base. Brasília: Ministério da Educação. Versão Final, 2018. 472 p. Disponível em: 〈https://bit.ly/2skbCls〉. Acesso em: 01/12/2018. 
BOMBASAR, J. R.; RAABE, A.; DE SANTIAGO, R. Design of a logic game for introducing computational thinking and computability concepts in basic education. Journal on Computational Thinking (JCThink), 2017. v. 1. n. 1. p. 03 - 15.

CRESWELL, J. W. Investigação Qualitativa e Projeto de Pesquisa: Escolhendo entre Cinco Abordagens. Penso Editora, $3^{\mathrm{a}}$ edição. 2014. 341 p.

DA SILVA JUNIOR, B. A.; CAVALHEIRO, S. A. C.; FOSS, L. "The last tree", exercising the computational thinking through a graph grammar based educational game. Journal on Computational Thinking (JCThink), 2018. v. 2. n. 1 p. 03 - 22.

FERREIRA, A. C. C.; MELHOR, A.; BARRETO, J. S.; DE PAIVA, L. F.; MATOS, E. Experiência prática interdisciplinar do Raciocínio Computacional em atividades de computação desplugada na Educação Básica. Anais do Workshop de Informática na Escola (XXI WIE), 2015. v. 21. n. 1. p. 256 - 265.

FRANÇA, R.; FERREIRA, V.; DE ALMEIDA, L.; DO AMARAL, H. A disseminação do pensamento computacional na educação básica: lições aprendidas com experiências de licenciandos em computação. Anais do Workshop sobre Educação em Computação (XXII WEI), 2014. p. 1473 - 1482.

GIBBS, G. Análise de Dados Qualitativos. Coleção Pesquisa Qualitativa. Artmed Editora, Porto Alegre - RS. 2009. 198 p.

KALELIOGLU, F.; GÜLBAHAR, Y.; KUKUL, V. A framework for Computational Thinking based on a systematic research review. Baltic Journal of Modern Computing, 2016. v. 4. n. 3. p. 583 - 596.

LEITE, M.; DA SILVA, S. F. Redimensionamento da computação em processo de ensino na educação básica: O pensamento computacional, o universo e a cultura digital. Anais do Workshop da Licenciatura em Computação (XXV WEI), 2017. v. 6. n. 1. p. $804-813$.

PIRES, M. F. C. Multidisciplinaridade, interdisciplinaridade e transdisciplinaridade no ensino. Interface - Comunicação, Saúde e Educação, 1998. p. 173 - 182.

RAABE, A.; METZGER, J.; GOMES, E.; VIEIRA, M. V.; SANTANA, A. L. M.; SOUZA, F. T.; RAMOS, G.; CUCCO, L. Características do Pensamento Computacional desenvolvidas em aprendizes do Ensino Médio por meio de atividades makers. Anais do Workshop de Informática na Escola (XXIII WIE), 2017. v. 23. n. 1. p. 145 - 154.

SBC. Computação na Educação Básica. XXXVII Congresso da Sociedade Brasileira de Computação. Versão Preliminar, 2017. 10 p. Disponível em: 〈https://goo.gl/NNdUv9〉. Acesso em: 20/07/2017.

VALENTE, J. A.; FREIRE, F. M. P.; ARANTES, F. L.; AMIEL, T.; BARANAUSKAS, M. C. C. Alan Turing tinha Pensamento Computacional? Reflexões sobre um campo em construção. Tecnologias, Sociedade e Conhecimento, 2017. v. 4. n. 1. p. 7 - 22.

WING, J. M. Computational Thinking. Communications of the ACM, 2006. v. 49. n. 3. p. $33-35$. 